\title{
Quality control of CarboEurope flux data - Part 2: Inter-comparison of eddy-covariance software
}

\author{
M. Mauder ${ }^{1, *}$, T. Foken ${ }^{1}$, R. Clement ${ }^{2}$, J. A. Elbers ${ }^{3}$, W. Eugster ${ }^{4}$, T. Grünwald ${ }^{5}$, B. Heusinkveld ${ }^{6}$, and O. Kolle ${ }^{7}$ \\ ${ }^{1}$ University of Bayreuth, Department of Micrometeorology, Bayreuth, Germany \\ ${ }^{2}$ University of Edinburgh, Institute of Ecology and Resource Management, Scotland \\ ${ }^{3}$ Alterra, Wageningen University and Research Centre, Wageningen, The Netherlands \\ ${ }^{4}$ ETH Zurich, Institute of Plant Sciences, Zurich, Switzerland \\ ${ }^{5}$ Technische Universität Dresden, Institute of Hydrology and Meteorology, Dresden, Germany \\ ${ }^{6}$ Wageningen University, Department of Meteorology and Air Quality, Wageningen, The Netherlands \\ ${ }^{7}$ Max-Planck-Institute for Biogeochemistry, Jena, Germany \\ *now at: Agriculture and Agri-Food Canada Research Branch, Ottawa, Ontario, Canada
}

Received: 17 October 2007 - Published in Biogeosciences Discuss.: 9 November 2007

Revised: 4 March 2008 - Accepted: 4 March 2008 - Published: 26 March 2008

\begin{abstract}
As part of the quality assurance and quality control activities within the CarboEurope-IP network, a comparison of eddy-covariance software was conducted. For four five-day datasets, $\mathrm{CO}_{2}$ flux estimates were calculated by seven commonly used software packages to assess the uncertainty of $\mathrm{CO}_{2}$ flux estimates due to differences in postprocessing. The datasets originated from different sites representing different commonly applied instrumentation and different canopy structures to cover a wide range of realistic conditions. Data preparation, coordinate rotation and the implementation of the correction for high frequency spectral losses were identified as crucial processing steps leading to significant discrepancies in the $\mathrm{CO}_{2}$ flux results. The overall comparison indicated a good although not yet perfect agreement among the different software within 5-10\% difference for 30-min $\mathrm{CO}_{2}$ flux values. Conceptually different ideas about the selection and application of processing steps were a main reason for the differences in the $\mathrm{CO}_{2}$ flux estimates observed. A balance should be aspired between scientific freedom on the one hand, in order to advance methodical issues, and standardisation of procedures on the other hand, in order to obtain comparable fluxes for multi-site synthesis studies.
\end{abstract}

Correspondence to: M. Mauder

(mauderm@agr.gc.ca)

\section{Introduction}

Within the worldwide network of carbon dioxide flux measurements between ecosystems and the atmosphere (FLUXNET, Baldocchi et al., 2001) the knowledge about possible errors and uncertainties is still one of the outstanding issues to be solved. After the eddy-covariance method has become widely used in the field of ecosystematmosphere exchange research (Moncrieff et al., 1997; Aubinet et al., 2000; Baldocchi et al., 2000) critical aspects of the method are still under investigation, e.g. averaging time (Finnigan et al., 2003), data quality control (Foken and Wichura, 1996; Foken et al., 2004), advection (Lee, 1998; Aubinet et al., 2003b; Staebler and Fitzjarrald, 2004), energy balance closure (Wilson et al., 2002; Foken, 2008), footprint (Göckede et al., 2004, 2006), gap filling (Falge et al., 2001; Ruppert et al., 2006a), scalar similarity (Pearson Jr. et al., 1998; Ruppert et al., 2006b) and others. The calculation and correction procedures for the eddy-covariance method have been described in the form of a user guide (Aubinet et al., 2003a). The influence of each step of the calculation procedure on the result is well known (Mauder and Foken, 2006b).

Only a few operators of FLUXNET stations developed their own software. Often commercially available software or the software of other groups is used. Each software has its benefits depending on the requirements of the user, e.g. online versus off-line calculation of fluxes, graphical outputs, control tools etc. However, the calculation and correction procedures should not differ between software packages that

Published by Copernicus Publications on behalf of the European Geosciences Union. 
Table 1. Test datasets for the software intercomparison.

\begin{tabular}{|c|c|c|c|c|}
\hline Abbrev. & Site & Canopy & $\begin{array}{l}\text { Measurement } \\
\text { height }\end{array}$ & Sensor set-up \\
\hline DE-Wei & $\begin{array}{l}\text { Waldstein-Weidenbrunnen site } \\
\text { of the University of Bayreuth } \\
\text { (UBT), Germany }\end{array}$ & $\begin{array}{l}\text { spruce } \\
19 \mathrm{~m}\end{array}$ & $33.0 \mathrm{~m}$ & Solent-R3/LI-7500 \\
\hline DE-Wet & $\begin{array}{l}\text { Wetzstein site of the Max-Planck- } \\
\text { Institute Jena, Germany }\end{array}$ & $\begin{array}{l}\text { spruce } \\
21 \mathrm{~m}\end{array}$ & $30.0 \mathrm{~m}$ & Solent-R3/LI-6262 \\
\hline G-ATEM & $\begin{array}{l}\text { GRASATEM-2003 dataset of } \\
\text { UBT, near Lindenberg, Germany } \\
\text { (Meteorological Observatory } \\
\text { of the German Meteorological } \\
\text { Service) }\end{array}$ & $\begin{array}{l}\text { grass } \\
0.12 \mathrm{~m}\end{array}$ & $2.26 \mathrm{~m}$ & USA-1/LI-7500 \\
\hline LIT-A6 & $\begin{array}{l}\text { LITFASS-2003 site A6 dataset of } \\
\text { UBT, near Lindenberg, Germany } \\
\text { (Beyrich and Mengelkamp, 2006) }\end{array}$ & $\begin{array}{l}\text { maize } \\
0.45 \mathrm{~m}\end{array}$ & $2.69 \mathrm{~m}$ & CSAT3/LI-7500 \\
\hline
\end{tabular}

process the same raw data time series with identical conceptual assumptions. It is shown (Mauder et al., 2007b) that this is not always the case, and even processing methods of internationally well established experimental groups can result in significantly different values for turbulent fluxes. Mauder et al. (2007b) find that deviations in the data processing methods can lead to differences of $10 \%$ for the sensible heat flux and of $15 \%$ for the latent heat flux for an averaging time of $30 \mathrm{~min}$. Large impacts on flux estimates are ascribed to sensor separation corrections and linear detrending of the data. As a result of this former intercomparison the TK2 (Mauder and Foken, 2004) algorithm was used for the analysis of the EBEX-2000 experiment (Oncley et al., 2007) to compute energy fluxes (Mauder et al., 2007b). The goal of this study is to investigate to which degree $\mathrm{CO}_{2}$ fluxes are influenced by differences in the post-field data processing methods. Our focus is on the software packages that are used by various research groups within the CarboEurope-IP framework. It is not intended to review the assumptions made in eddy-covariance flux measurements, rather to validate whether different software produce the same or at least comparable results for $\mathrm{CO}_{2}$ fluxes based on more or less similar assumptions.

\section{Datasets and software}

In order to address this issue, several developers of eddycovariance software were asked to process four different datasets of five days length representing different site conditions and different sensor set-ups, which are commonly used in the CarboEurope-IP network. Supplying datasets for this intercomparison study was voluntary. Therefore, the different test datasets do not cover all possible places and sensor combinations and not all software used in CarboEurope-IP was included. The selected datasets are given in Table 1.
Two typical installations for European forest sites with the sonic anemometer Solent R3 (Gill Instruments Ltd., UK) and the open- and closed-path gas analysers LI-7500 and LI6262 (Li-Cor Biosciences, USA) were used. Furthermore, two other sonic anemometers, USA-1 (METEK GmbH, Germany) and CSAT3 (Campbell Scientific Inc., USA), were used in combination with an open-path gas analyser over low vegetation.

It is generally important for the applicability of software that a sufficient automatic quality control is implemented. Therefore, these test datasets contained real measurements with data gaps, spikes and other data quality problems that actually occurred during standard operations. They were not idealized data on purpose, expecting that the results would not only reveal differences about implicit methods used by the different software packages, but also about implicit assumptions and conceptual differences between them. An important idea was that periods of low data quality had to be detected and discarded automatically during the data postprocessing by the different software. The challenge for the software producer was thus to find a compromise to exclude low-quality data with a high certainty and still to retain as much of the good data as possible to allow for the best possible estimate of long-term sums.

The originally measured raw data were converted to the newly defined standardised CarboEurope Data Exchange Format CDEF (Mauder and Foken, 2004). Since each group started the processing with an identical time series, one can expect the computed fluxes to be quite similar if all algorithms feature the same processing steps and make the same implicit methodological assumptions. However, the software packages under study show indeed some differences. The characteristics of each of them are given in Table 2 .

In many of the post-field data processing methods a spike detection algorithm was implemented (Højstrup, 1993; 
Table 2. Processing steps of eddy-covariance software (status 2005/2006).

\begin{tabular}{|c|c|c|c|c|c|c|c|}
\hline Software & TK2 & Alteddy & ECPack & EddySoft & EdiRE & eth-flux & TUDD \\
\hline Data sampling & $\begin{array}{l}\text { CSAT3, } \\
\text { USA-1,HS, } \\
\text { R2,R3,ATI- } \\
\text { K,NUW, Young; } \\
\text { 6262,7000, } \\
\text { 7500,KH20, ADC } \\
\text { OP-2 }\end{array}$ & $\begin{array}{l}\text { R2,R3,WMPro; } \\
\text { CSAT3,USA-1, } \\
6262,7500, \\
\text { KH20 }\end{array}$ & $\begin{array}{l}\text { R2,R3,CSAT3 } \\
\text { KDTR90/TR61 } \\
7500, \text { KH20, } \\
\text { Lyman- } \alpha\end{array}$ & $\begin{array}{l}\text { R2,R3, Young; } \\
6262,7000 \text {, } \\
\text { 7500, ADC OP-2 }\end{array}$ & Any & $\begin{array}{l}\text { R2,R3,HS; } \\
\text { 6262,7500,FM- } \\
\text { 100, MonitorLabs, } \\
\text { Scintrex LMA3 }\end{array}$ & $\begin{array}{l}\text { R2,R3,HS, } \\
\text { USA-1; } \\
6262,7000\end{array}$ \\
\hline Data preparation & $\begin{array}{l}\text { Test plausibility, } \\
\text { spikes; } \\
\text { Block average; } \\
\text { Time lag } \\
\text { const/auto }\end{array}$ & $\begin{array}{l}\text { Test plausibility, } \\
\text { spikes; } \\
\text { Block average; } \\
\text { optional detrending } \\
\text { (filter); } \\
\text { Time lag } \\
\text { const/auto }\end{array}$ & $\begin{array}{l}\text { Test plausibility, } \\
\text { spikes; } \\
\text { optional detrending } \\
\text { (linear); } \\
\text { Time lag const. }\end{array}$ & $\begin{array}{l}\text { Test plausibility, } \\
\text { spikes; } \\
\text { Block average, op- } \\
\text { tional detrending; } \\
\text { Time lag } \\
\text { const/auto }\end{array}$ & $\begin{array}{l}\text { Test plausibility, } \\
\text { spikes; } \\
\text { optional detrending } \\
\text { (linear/filter); } \\
\text { Block average; } \\
\text { Time lag } \\
\text { const/auto }\end{array}$ & $\begin{array}{l}\text { Test plausibility, } \\
\text { spikes; } \\
\text { Block average, op- } \\
\text { tional detrending; } \\
\text { Time lag } \\
\text { const/auto }\end{array}$ & $\begin{array}{l}\text { Test plausibility; } \\
\text { Block average; } \\
\text { Time lag for closed } \\
\text { path sensor }\end{array}$ \\
\hline Coordinate rotation & $\begin{array}{l}\text { planar fit/ } \\
\text { 2-D rotation; } \\
\text { Head-correction }\end{array}$ & $\begin{array}{l}\text { 2-D rotation; } \\
\text { Angle-of-attack }\end{array}$ & $\begin{array}{l}\text { planar fit/ } \\
\text { 2-D/3-D rotation }\end{array}$ & $\begin{array}{l}\text { planar fit/ } \\
\text { 2-D/3-D rotation }\end{array}$ & $\begin{array}{l}\text { planar fit/ } \\
\text { 2-D/3-D rotation }\end{array}$ & 2-D/3-D rotation & 3-D rotation \\
\hline $\begin{array}{l}\text { Buoyancy flux } \rightarrow \\
\text { sensible heat flux }\end{array}$ & $\begin{array}{l}\text { Schotanus et al. } \\
(1983) / \\
\text { Liu et al. } \\
(2001)\end{array}$ & $\begin{array}{l}\text { Schotanus et al. } \\
\text { (1983) }\end{array}$ & $\begin{array}{l}\text { Schotanus et al. } \\
\text { (1983) }\end{array}$ & $\begin{array}{l}\text { Schotanus et al. } \\
(1983) / \\
\text { Liu et al. } \\
(2001)\end{array}$ & $\begin{array}{l}\text { Schotanus et al. } \\
(1983) / \\
\text { Liu et al. } \\
(2001)\end{array}$ & - & $\begin{array}{l}\text { Schotanus et al. } \\
(1983) / \\
\text { Liu et al. } \\
(2001)\end{array}$ \\
\hline $\begin{array}{l}\text { Oxygen correction } \\
\text { hygrometer }\end{array}$ & $\begin{array}{l}\text { Tanner et al. } \\
\text { (1993) }\end{array}$ & $\begin{array}{l}\text { Tanner et al. } \\
(1993) / \\
\text { van Dijk et al. } \\
(2003)\end{array}$ & $\begin{array}{l}\text { Tanner et al. } \\
(1993) / \\
\text { van Dijk et al. } \\
(2003)\end{array}$ & - & - & - & - \\
\hline $\begin{array}{l}\text { High frequency } \\
\text { loss }\end{array}$ & Moore (1986) & $\begin{array}{l}\text { Moore }(1986) / \mathrm{Eu}- \\
\text { gster and Senn } \\
(1995)\end{array}$ & Moore (1986) & $\begin{array}{l}\text { Eugster and Senn } \\
\text { (1995) }\end{array}$ & $\begin{array}{l}\text { Moore }(1986) / \mathrm{Eu}- \\
\text { gster and Senn } \\
(1995)\end{array}$ & $\begin{array}{l}\text { Eugster and Senn } \\
\text { (1995) }\end{array}$ & $\begin{array}{l}\text { Moore (1986)/Eu- } \\
\text { gster and Senn } \\
(1995)\end{array}$ \\
\hline WPL correction & Webb et al. (1980) & Webb et al. (1980) & Webb et al. (1980) & Webb et al. (1980) & Webb et al. (1980) & Webb et al. (1980) & Webb et al. (1980) \\
\hline $\begin{array}{l}\text { Iteration of all cor- } \\
\text { rections }\end{array}$ & yes & - & yes & - & yes & - & - \\
\hline Calculation & $\begin{array}{l}\lambda(\mathrm{T}) ; \operatorname{cp}\left(\mathrm{c}_{p, \text { dry }}, \mathrm{q}\right) ; \\
\rho(\mathrm{T}, \mathrm{p})\end{array}$ & $\begin{array}{l}\lambda(\mathrm{T}) ; \mathrm{c}_{p}=\text { const.; } \\
\rho(\mathrm{T}, \mathrm{p})\end{array}$ & $\begin{array}{l}\lambda(\mathrm{T}) ; \mathrm{c}_{p}=\text { const.; } \\
\rho(\mathrm{T}, \mathrm{p})\end{array}$ & $\begin{array}{l}\lambda(\mathrm{T}) ; \mathrm{c}_{p}=\text { const.; } \\
\rho(\mathrm{T}, \mathrm{p})\end{array}$ & $\begin{array}{l}\lambda(\mathrm{T}) ; \mathrm{c}_{p}(c p, \mathrm{dry}, \mathrm{q}) \\
\rho(\mathrm{T}, \mathrm{p})\end{array}$ & $\begin{array}{l}\lambda(\mathrm{T}) ; \mathrm{c}_{p}=\text { const.; } \\
\rho(\mathrm{T}, \mathrm{p})\end{array}$ & $\begin{array}{l}\lambda(\mathrm{T}) ; \mathrm{c}_{p}=\text { const.; } \\
\rho(\mathrm{T})\end{array}$ \\
\hline Quality control & $\begin{array}{l}\text { Test steady state, } \\
\text { integral turbulence } \\
\text { characteristics: Fo- } \\
\text { ken and Wichura } \\
(1996)\end{array}$ & uncertainty factor & $\begin{array}{l}\text { statistical error: } \\
\text { van Dijk et al. } \\
(2004)\end{array}$ & $\begin{array}{l}\text { Test steady state, } \\
\text { integral turbulence } \\
\text { characteristics: Fo- } \\
\text { ken and Wichura } \\
\text { (1996); Footprint }\end{array}$ & $\begin{array}{l}\text { Test steady state, } \\
\text { integral turbulence } \\
\text { characteristics: } \\
\text { Foken and Wichura } \\
\text { (1996), Vickers } \\
\text { and Mahrt (1997); } \\
\text { Footprint }\end{array}$ & $\begin{array}{l}\text { Test steady state, } \\
\text { integral turbulence } \\
\text { characteristics: Fo- } \\
\text { ken and Wichura } \\
(1996)\end{array}$ & $\begin{array}{l}\text { nighttime critical } \\
u_{*}\end{array}$ \\
\hline
\end{tabular}

Vickers and Mahrt, 1997). From the despiked time series covariances can be calculated after either block averaging or linear detrending. Coordinate systems can be transformed either by using two or three dimensional rotation (Kaimal and Finnigan, 1994) or according to the planar fit method (Wilczak et al., 2001). If no additional fast response thermometer is available the vertical sonic temperature flux (buoyancy flux) has to be converted into the sensible heat flux either according to the equation by Schotanus et al. (1983) or by Liu et al. (2001). A cross wind correction has to be applied only if such is not implemented in the internal software of the sonic anemometer. If Lyman-alpha or krypton hygrometers are used a correction for the cross-sensitivity to oxygen has to be applied (Tanner et al., 1993; van Dijk et al., 2003). The software packages compared in this study employed the approaches of by Moore (1986) and Eugster and Senn (1995) to correct for spectral losses. When measuring fluxes of air constituents in volume-related units (in contrast to mass-related ratios such as dry mole fractions) the so called WPL-correction (Webb et al., 1980) has to be applied in order to compensate for density fluctuations and a vertical mass flow. No additional corrections to the original WPLapproach, such as the influence of the lack of energy balance closure (Liu et al., 2006), the effects of window dirtiness (Serrano-Ortiz et al., 2008), or sensor induced density fluctuations (Grelle and Burba, 2007) were applied. All processing steps after the calculation of the covariances were carried out iteratively in some of the software packages because of their partial interdependence. Finally, it makes a difference if physical "constants" like the specific heat of evaporation $\lambda$ or the specific heat capacity of the air at a constant pressure $c_{p}$ are assumed to be constant or if their dependence on temperature and moisture are taken into account. Tools proposed by Foken and Wichura (1996) or Vickers and Mahrt (1997) can be applied for quality assessment and quality control of eddy covariance flux measurements.

The participants of this software comparison were asked to follow a certain processing scheme, if possible with their 
software, in order to minimise discrepancies due to a different selection of procedures by the user. Based on the recommendations of Lee et al. (2004), the following processing steps should be applied.

Data preparation:

- no detrending

- block averaging $30 \mathrm{~min}$

- electrical and physical plausibility

- spike removal (e.g. Højstrup, 1993)

- auto detection of time delay between different sensors

Conversions and Corrections:

- Cross wind correction of sonic temperature for SolentR2 and USA-1 (Liu et al., 2001)

- Planar fit coordinate rotation (Wilczak et al., 2001)

- Correction of high frequency spectral losses (e.g. Moore, 1986)

- Conversion of buoyancy flux (measured with sonic temperature) into the sensible heat flux (Schotanus et al., 1983)

- Density correction for open-path analysers (Webb et al., 1980)

- Consideration of interdependence of corrections, e.g. by iteration.

\section{Quality Assurance and Quality Control (QA/QC)}

- Quality test after the description of the QA/QC programme according to Foken and Wichura (1996) with three quality classes (Mauder and Foken, 2004). These tests check for stationarity and well-developed turbulence based on flux-variance similarity.

All the software packages listed in Table 2 are commonly used in the CarboEurope-IP network. For practical reasons, one of the software packages was chosen as a reference for the analysis of this comparison. The TK2 software (Mauder and Foken, 2004) of the University of Bayreuth is very comprehensive and was already tested in another international software comparison (Mauder et al., 2007b). The data analysis scheme of the TK2 software package implements the recommendations of a workshop covering methodological aspects of eddy-covariance measurements (Lee et al., 2004). It was therefore chosen as reference for this comparison. Although the TK2 results cannot really be an absolute independent reference, it is treated as such in the regression analysis for this comparison, i.e. the inverted regression equations given below could theoretically be used to "calibrate" the results of the other software packages to the TK2 results.
The Alteddy software was developed at the ALTERRA institute in Wageningen. It had been restricted to Solent sonics prior to this study, but was extended to be able to deal with CSAT3 and USA-1 data for this software comparison. All flux results for this study were obtained by block averaging. A second flux was calculated using a running mean, which allows calculating a "detrending uncertainty" as quality criterion. Alteddy was not capable of performing a planar fit coordinate transformation. As an additional feature, not found in all other algorithms, Alteddy implemented an angle-ofattack dependent flow distortion correction (Gash and Dolman, 2003; van der Molen et al., 2004). The quality control is based on self-developed test parameters, which are similar to the steady state test of Vickers and Mahrt (1997). Further, a spike detection algorithm is included, also following the procedure proposed by Vickers and Mahrt (1997).

Most of the processing steps in the software ECPack from Wageningen University were similar to the algorithm of TK2. This is partly a result of collaborations between both institutes for more than five years (Mauder et al., 2007b). ECPack usually uses a linear detrending for data preparation, but this function was switched off for this intercomparison study. A self-developed quality control tool was applied calculating a statistical error (van Dijk et al., 2004).

EddySoft (Kolle and Rebmann, 2007), developed at the Max-Planck-Institute for Biogeochemistry in Jena, also had an algorithm very similar to the TK2 software from Bayreuth because of the close connection of one of the authors to the University of Bayreuth (C. Rebmann). Only the correction for high frequency spectral losses was different. The inductance concept of Eugster and Senn (1995) is applied instead of the approach by Moore (1986). Both concepts are based on idealized spectral models and analytical transfer functions. However, Eugster and Senn (1995) use a transfer function for the integrated cospectrum.

The EdiRE software from the University of Edinburgh is a very complete software package including all options necessary for processing eddy covariance data similar to TK2. Larger discrepancies in the resulting $\mathrm{CO}_{2}$ fluxes compared to TK2 could only be explainable if certain procedures are implemented differently in the software source code, or if different procedures were selected by the user of the software.

The eth-flux software, developed by W. Eugster from the ETH Zurich, is generally only used for eddy-covariance systems with Solent sonics running in calibrated mode (and extension to CSAT3 sonics is in progress but was not available during the time of this comparison). However, data from the Metek USA-1 sonic were also processed for this intercomparison. This software did not include the planar fit method for coordinate transformation. An automatic statistical spike detection routine can be switched on, see Eugster (1997), for noisy instruments, but was not applied for any of the datasets of this intercomparison since the concept followed at ETH is to avoid spikes during data acquisition using a rigorous 
Table 3. Results of the regression analyses of the $\mathrm{CO}_{2}$ flux estimates calculated by the different software packages; TK2 data are chosen as references and independent variable.

\begin{tabular}{|c|c|c|c|c|c|c|c|c|c|c|c|c|}
\hline Software & slope & $\begin{array}{l}\text { DE-Wei } \\
\text { tall vegetation } \\
\mathrm{R} 3, \mathrm{LI}-7500 \\
\text { intercept } \\
\left(\mu \mathrm{mol} \mathrm{s}^{-1} \mathrm{~m}^{-2}\right)\end{array}$ & $\mathrm{R}^{2}$ & slope & $\begin{array}{l}\text { DE-Wet } \\
\text { tall vegetation } \\
\text { R3, LI-6262 } \\
\text { intercept } \\
\left(\mu \mathrm{mol} \mathrm{s}^{-1} \mathrm{~m}^{-2}\right)\end{array}$ & $\mathrm{R}^{2}$ & slope & $\begin{array}{l}\text { G-ATEM } \\
\text { low vegetation } \\
\text { USA-1, LI-7500 } \\
\text { intercept } \\
\left(\mu \mathrm{mol} \mathrm{s}^{-1} \mathrm{~m}^{-2}\right)\end{array}$ & $\mathrm{R}^{2}$ & slope & $\begin{array}{l}\text { LIT-A6 } \\
\text { low vegetation } \\
\text { CSAT3, LI-7500 } \\
\text { intercept }\left(\mu \mathrm{mol} \mathrm{s}^{-1}\right. \\
\left.\mathrm{m}^{-2}\right)\end{array}$ & $\mathrm{R}^{2}$ \\
\hline Alteddy & $\begin{array}{l}1.08 \\
\pm 0.02\end{array}$ & $\begin{array}{l}-0.3 \\
\pm 0.1\end{array}$ & 0.95 & $\begin{array}{l}0.98 \\
\pm 0.01\end{array}$ & $\begin{array}{l}-0.2 \\
\pm 0.1\end{array}$ & 0.98 & $\begin{array}{l}0.91 \\
\pm 0.02\end{array}$ & $\begin{array}{l}-0.4 \\
\pm 0.2\end{array}$ & 0.86 & $\begin{array}{l}1.08 \\
\pm 0.02\end{array}$ & $\begin{array}{l}-0.2 \\
\pm 0.1\end{array}$ & 0.96 \\
\hline ECPack*) & - & - & - & - & - & - & - & - & - & $\begin{array}{l}0.76 \\
\pm 0.01\end{array}$ & $\begin{array}{l}+0.2 \\
\pm 0.1\end{array}$ & 0.96 \\
\hline EddySoft & $\begin{array}{l}0.97 \\
\pm 0.00\end{array}$ & $\begin{array}{l}+0.1 \\
\pm 0.0\end{array}$ & 1.00 & $\begin{array}{l}1.05 \\
\pm 0.00\end{array}$ & $\begin{array}{l}+0.1 \\
\pm 0.0\end{array}$ & 1.00 & $\begin{array}{l}0.87 \\
\pm 0.01\end{array}$ & $\begin{array}{l}-0.2 \\
\pm 0.1\end{array}$ & 0.96 & $\begin{array}{l}0.94 \\
\pm 0.01\end{array}$ & $\begin{array}{l}+0.2 \\
\pm 0.0\end{array}$ & 0.98 \\
\hline EdiRE & $\begin{array}{l}0.99 \\
\pm 0.01\end{array}$ & $\begin{array}{l}-0.1 \\
\pm 0.1\end{array}$ & 0.98 & $\begin{array}{l}1.05 \\
\pm 0.01\end{array}$ & $\begin{array}{l}-0.2 \\
\pm 0.1\end{array}$ & 0.99 & $\begin{array}{l}0.93 \\
\pm 0.01\end{array}$ & $\begin{array}{l}+0.0 \\
\pm 0.1\end{array}$ & 0.97 & $\begin{array}{l}0.90 \\
\pm 0.01\end{array}$ & $\begin{array}{l}+0.2 \\
\pm 0.1\end{array}$ & 0.97 \\
\hline eth-flux & $\begin{array}{l}1.06 \\
\pm 0.01\end{array}$ & $\begin{array}{l}-0.3 \\
\pm 0.1\end{array}$ & 0.97 & $\begin{array}{l}1.03 \\
\pm 0.00\end{array}$ & $\begin{array}{l}-0.2 \\
\pm 0.0\end{array}$ & 1.00 & $\begin{array}{l}0.90 \\
\pm 0.03\end{array}$ & $\begin{array}{l}-1.0 \\
\pm 0.2\end{array}$ & 0.86 & - & - & - \\
\hline TUDD*) & - & - & - & $\begin{array}{l}1.05 \\
\pm 0.01\end{array}$ & $\begin{array}{l}-0.2 \\
\pm 0.1\end{array}$ & 0.98 & - & - & - & - & - & - \\
\hline
\end{tabular}

* These software packages were already compared to TK2 within the EBEX-2000 project in 2002 (Mauder et al., 2007).

checking of incoming data. The correction for high frequency spectral loss was conducted according to Eugster and Senn (1995). The other processing steps were similar to TK2 including the quality tests according to Foken and Wichura (1996).

The TUDD software from the University of Technology Dresden is restricted to closed-path infra-red gas analysers (IRGAs). Therefore, the developers decided not to incorporate some of the processing steps which are common to the other software packages in this intercomparison study. The TUDD software had no statistical despiking routine; only values outside a plausible range are excluded. An optional planar fit coordinate transformation was not available. The calculation of physical constants is simplified. This software is similar to the University of Basel software, which was already compared with TK2 in an earlier study (Mauder et al., 2007b).

\section{Results and discussion for each dataset}

The focus of this intercomparison was solely on the $\mathrm{CO}_{2}$ flux estimates. Therefore, only $\mathrm{CO}_{2}$ flux estimates from the different software packages are presented here. However, the results for other fluxes, variances and mean values were also considered to explain discrepancies, although these data are not shown. A regression analyses was conducted to quantify the deviations between the flux results of the different software packages. The results are given in Table 3. If the three-class quality flags were provided according to the processing scheme, then data of lowest the quality class were excluded from the comparison. Eth-flux was the only software in this intercomparison, except TK2, that applied the required three-class quality flag system. Therefore, only for this software, quality-flag filtered $\mathrm{CO}_{2}$ flux estimates could be compared. For the other software packages, extreme out- liers were discarded, i.e. if the squared distance from the TK2 result for a specific 30-min interval was greater than $1000 \mu \mathrm{mol}^{2} \mathrm{~m}^{-4} \mathrm{~s}^{-2}$. The $\mathrm{CO}_{2}$ flux estimates from all software packages were plotted against those from the TK2 software for comparison (Figs. 1-5).

The five-day dataset from the site WaldsteinWeidenbrunnen (DE-Wei) was measured in July 2003 using a Solent-R3 sonic and a LI-7500 open-path IRGA on a $32 \mathrm{~m}$ tower over a spruce forest. The data were processed by Alteddy, EddySoft, EdiRE, eth-flux and TK2 (Fig. 1). The slopes of the regression lines ranged between 0.97 and 1.08 (Table 3). A few data points showed larger deviations from TK2. Different despiking routines may have caused these deviations. The EddySoft results were almost identical with the TK2 estimates, except for three values that were approximately $3 \mu \mathrm{mol} \mathrm{m}^{-2} \mathrm{~s}^{-1}$ above the $1: 1$ line. The $\mathrm{CO}_{2}$ flux estimates of EdiRE were also almost identical to the TK2 results, except for two outliers. The other two software packages computed slightly larger negative fluxes. The Alteddy fluxes were more than $10 \%$ larger than the TK2, EddySoft and EdiRE results for daytime periods. The eth-flux results were $6 \%$ larger on average. Part of the deviations of the Alteddy results can be explained by the angle-of-attack calibration (van der Molen et al., 2004). Had this been switched off, then the results would probably have come closer to the 1:1 line. The reason for the larger negative fluxes produced by the eth-flux software remains unclear.

The eddy-covariance system of the Wetzstein site (DEWet) was located over a $21 \mathrm{~m}$ tall spruce forest. The data were measured by a Solent-R3 sonic anemometer and a LI6262 closed-path IRGA in July 2003. These data were processed by Alteddy, EdiRE, EddySoft, eth-flux, TUDD and TK2 (Fig. 2). The WPL correction term was negligibly small for this dataset because only the correction for a vertical 


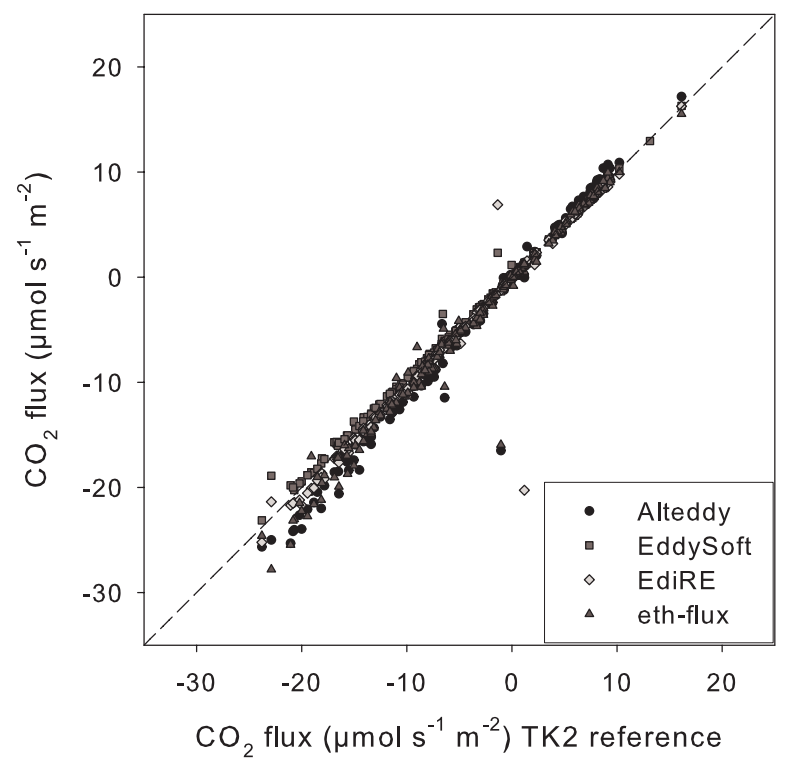

Fig. 1. $\mathrm{CO}_{2}$ flux estimates from the site Waldstein-Weidenbrunnen over spruce forest of $19 \mathrm{~m}$ canopy height (Solent-R3/LI-7500), calculated by the software packages Alteddy, EddySoft, eth-flux and TK2 as reference.

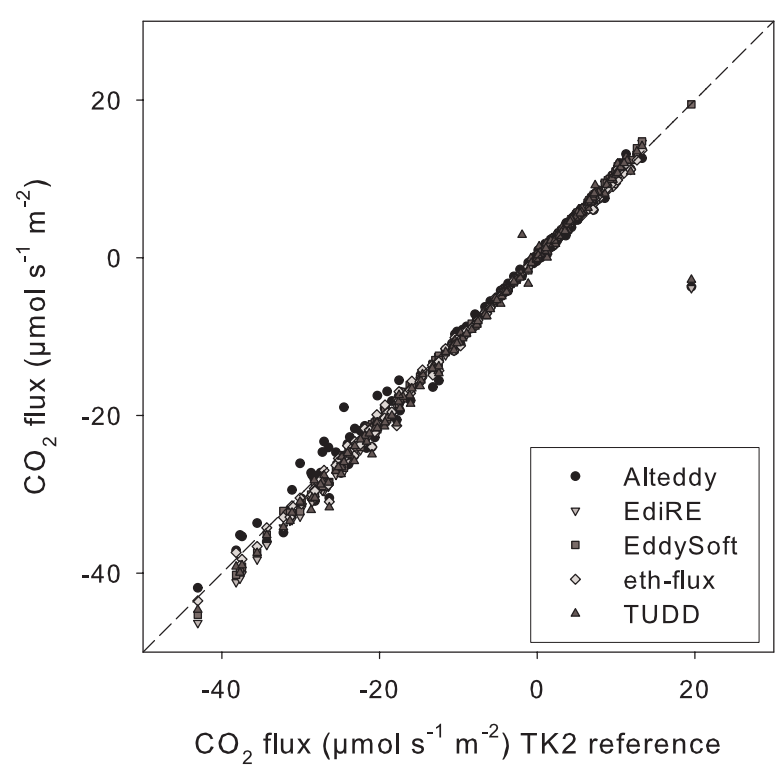

Fig. 2. $\mathrm{CO}_{2}$ flux estimates from the site Wetzstein over evergreen needleleaf forest of $21 \mathrm{~m}$ canopy height (Solent-R3/LI-6262), calculated by the software packages Alteddy, EdiRE, EddySoft, eth-flux, TUDD and TK2 as reference.

positive moisture flow was necessary, since atmospheric $\mathrm{CO}_{2}$ is directly measured in units of mole fraction at constant temperature and pressure inside the analyser, which eliminates the need for a sensible heat flux correction. One difficulty of this dataset was to find an appropriate correction for the tube delay of the closed-path system. Most of the participants

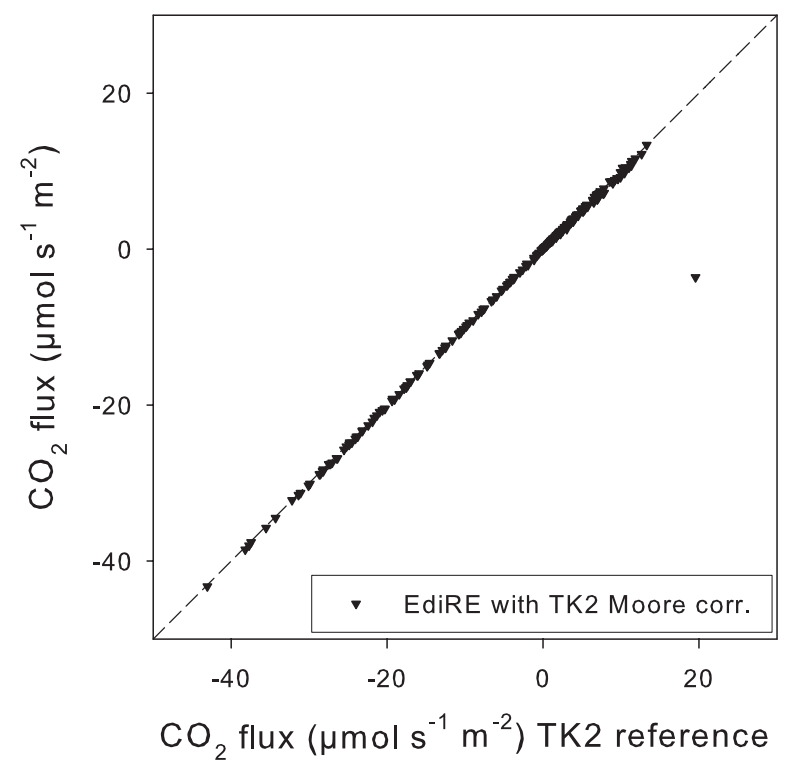

Fig. 3. $\mathrm{CO}_{2}$ flux estimates computed from the same dataset as Fig. 2 using EdiRE, but replacing EdiRE's spectral correction by TK2's spectral correction.

managed this task similarly well using a cross-correlation analysis to determine the lag for the maximum covariance.

The results of the software packages EddiSoft, EdiRE and TUDD were slightly higher than those from TK2. The slopes of their regression lines were 1.05. The reason was possibly the spectral correction. The EdiRE fluxes, for example, were almost exactly on the 1:1 line, when the EdiRE's Moore correction was replaced by TK2's Moore correction (Fig. 3). EdiRE's spectral correction was different from TK2's, since it has a tube attenuation correction, and it not only corrects for high-frequency losses but also for low-frequency losses due to a limited averaging time when applying block averaging. Similarly to EdiRE, TUDD's spectral correction used transfer functions of Moore (1986) and Leuning and King (1992) with the exception of the correction for limited averaging time. EddiSoft used the damping loss correction proposed by Eugster and Senn (1995), and gives probably therefore slightly different results. The Alteddy results did not show this systematic difference as compared to the TK2. However, more scatter can be seen for negative (downward) $\mathrm{CO}_{2}$ flux estimates. The eth-flux results were relatively close to the TK2 results for this site, with very little scatter.

There is one outlier in Fig. 2 representing an interval in the morning of 7 July 2003 between 09:00 CET and 09:30 CET. TK2 and EddySoft gave a $\mathrm{CO}_{2}$ flux of around $+19 \mu \mathrm{mol} \mathrm{m}^{-2} \mathrm{~s}^{-1}$ for this specific 30-min interval. Alteddy, EdiRE and TUDD calculated a value of around $-3 \mu \mathrm{mol} \mathrm{m}{ }^{-2} \mathrm{~s}^{-1}$. The eth-flux software discarded this value after the quality tests. The same test result was obtained from the TK2 software. However, we didn't exclude any TK2 data due to poor quality tests, to allow comparing 


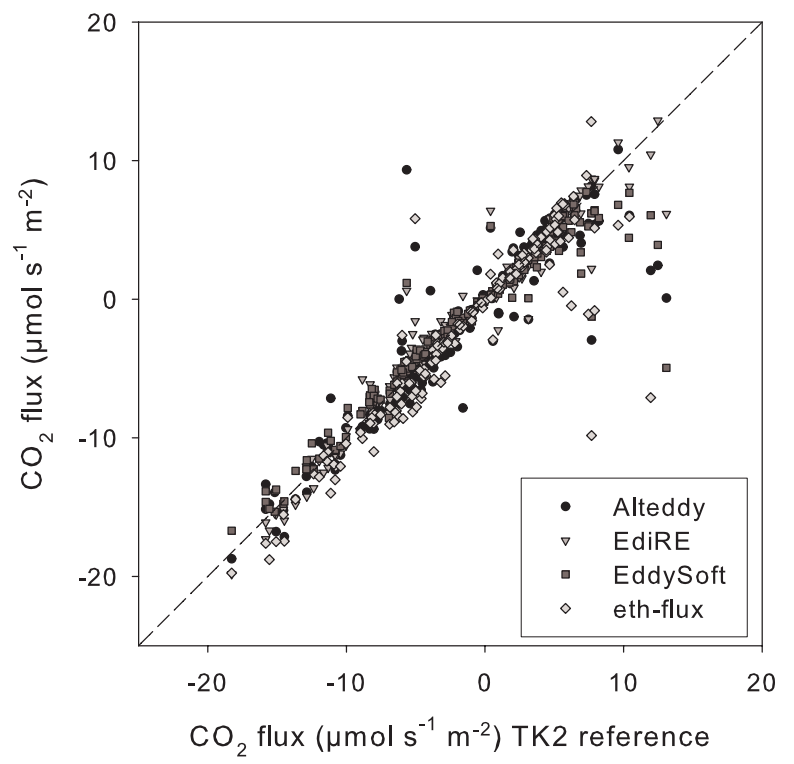

Fig. 4. $\mathrm{CO}_{2}$ flux estimates from the site GRASATEM-2003 over grassland of $0.12 \mathrm{~m}$ canopy height (USA-1/LI-7500), calculated by the software packages Alteddy, EdiRE, EddySoft, eth-flux and TK2 as reference.

the results of other software packages with them. The discrepancies for this interval are most probably due to the spike elimination routine. The TK2 test based on an algorithm proposed by Vickers and Mahrt (1997) detected 1022 of 36000 values in this interval as spikes. EddySoft used a similar algorithm with similar parameters, whereas the other software packages applied a different variant of the spike test. Alteddy, for example, applied a similar algorithm with different parameter settings, i.e. the window length was only $1 \mathrm{~s}$ for wind speeds instead of $15 \mathrm{~s}$ for the TK2.

It is difficult to judge which of the two different estimates is closer to the true value, since no absolute independent reference is available. This clearly documents the necessity to carefully consider implicit conceptual assumptions made by the developer of a data processing software that go well beyond the pure physical and statistical correctness of the computations. This outlier occurred directly after a system maintenance interval and the data seem to be disturbed. Discarding this 30-min value is probably the best choice due to the too large number of spikes. Only the QA/QC test performed by eth-flux was capable of identifying this problem. It should be noted that eth-flux did not use a spike filter but relied on the quality control to be able to detect such problems in the time series. This is another documentation of how different conceptual approaches can lead to different results irrespective of the correct implementation of statistical algorithms.

The GRASATEM-2003 (G-ATEM) site was equipped with a Metek USA-1 sonic and a LI-7500 open-path IRGA (Mauder et al., 2003). The eddy-covariance system was established at a measurement height of $2.26 \mathrm{~m}$ over short grass.

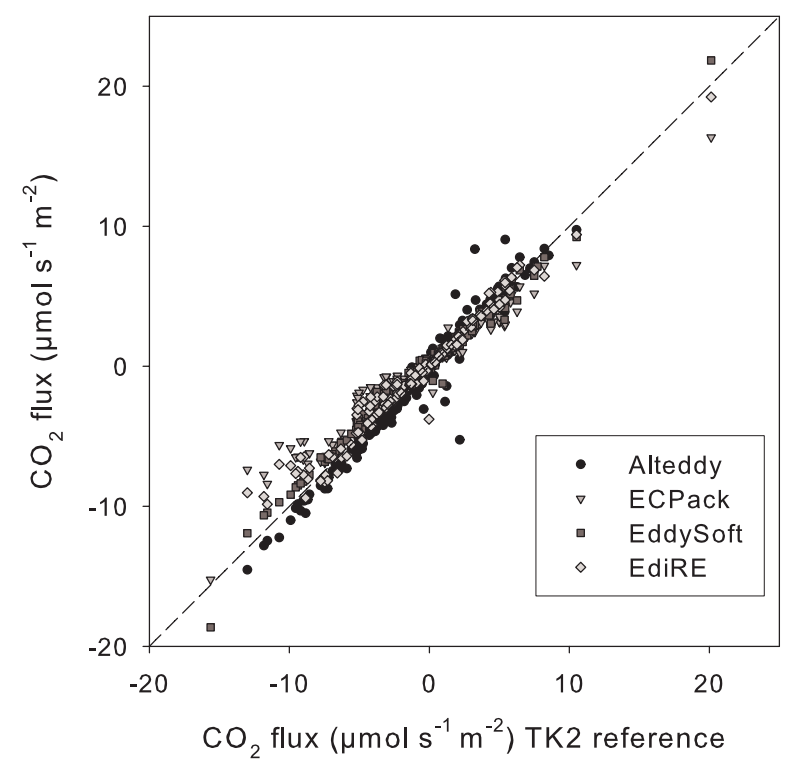

Fig. 5. $\mathrm{CO}_{2}$ flux estimates from the site A6 of LITFASS-2003 over maize of $0.45 \mathrm{~m}$ canopy height (CSAT3/LI-7500), calculated by the software packages Alteddy, ECPack, EddySoft, EdiRE and TK2 as reference.

The dataset was collected in May 2003. The site was located in a terrain depression, where $\mathrm{CO}_{2}$ accumulated under very stable stratification in clear nights. This led together with the relatively low measurement height sometimes to very high values for $\mathrm{CO}_{2}$ density at the measurement level, partly also with a large variance. Further, dewfall occurred in some of the nights, leading to spikes in the $\mathrm{CO}_{2}$ signal. Very light winds with velocities below $0.5 \mathrm{~m} \mathrm{~s}^{-1}$ occurred during two of the five nights in the selected period. The G-ATEM dataset was processed by Alteddy, EdiRE, EddySoft, eth-flux and TK2 (Fig. 4). The EddySoft data agreed quite well with the TK2 results for most of the time. However, during periods of large positive $\mathrm{CO}_{2}$ fluxes at nighttime, the EddySoft fluxes were smaller than those of the TK2. This led to a slope of the regression line of 0.87 . Since the flux corrections were very small for these periods, the deviations have to be due to the data preparation, e.g. spike elimination or delay correction. The results of Alteddy, EdiRE and eth-flux did not show such systematically different results compared to TK2 (Table 3). The scatter of the EdiRE results is small $\left(R^{2}=0.97\right)$. The few larger deviations from the TK2 occurred during nighttime, which points to differences in the spike elimination.

The results from Alteddy $\left(R^{2}=0.86\right)$ and eth-flux $\left(R^{2}=0.86\right)$ showed a relatively large amount of scatter. It cannot be decided from the pure comparison with TK2 which of these software yields the best estimates for the $\mathrm{CO}_{2}$ flux, although the relatively good agreement of EdiRE and TK2 supports the credibility of the results from both of these software packages. The discrepancies of Alteddy and eth-flux can probably be ascribed to the data preparation. Alteddy 
and eth-flux both employ the double rotation method in place of the planar fit method. This would mean that both coordinate transformation methods agree in most of the cases very well and only under certain conditions, e.g. light winds at night, larger differences between double rotated and planar fit transformed data occur. Similar findings are also reported by Mauder and Foken (2006a) for a different dataset. Selected cases, where eth-flux and TK2 differed the most, were investigated in more detail. Large eth-flux rotation angles up to $10^{\circ}$ can only partly explain the differences. Furthermore, the automatic delay correction caused different results during periods where the three wind components and the $\mathrm{CO}_{2}$ concentration showed significant drifts. In TK2 a crosscorrelation analysis is applied to the uncorrected time series, whereas in eth-flux the cross-correlation analysis is applied to the coordinate-rotated time series. This difference resulted in different lags for the maximum covariance of almost one $1 \mathrm{~s}$ for some 30-min intervals, leading to large differences in the $\mathrm{CO}_{2}$ flux estimates even of opposite sign.

Site A6 (LIT-A6) of the LITFASS-2003 field campaign (Mauder et al., 2006) was located on a maize field of $0.45 \mathrm{~m}$ canopy height. A CSAT3 sonic was installed together with a LI-7500 open-path IRGA at a height of $2.69 \mathrm{~m}$ above ground level. Alteddy, ECPack, EddySoft, EdiRE and TK2 processed five days of data from this site, which had been measured in June 2003 (Fig. 5). The data calculated by EddySoft agreed very well with the TK2 results (see also Table 3 ). The results of EdiRE also agreed almost perfectly with TK2 for positive and slightly negative $\mathrm{CO}_{2}$ fluxes. However, during periods of large negative $\mathrm{CO}_{2}$ fluxes and high friction velocities, EdiRE fluxes were sometimes smaller than the TK2 estimates. From the ECPack software, smaller $\mathrm{CO}_{2}$ fluxes than both EdiRE and TK2 were obtained for most of the dataset. This difference was more pronounced during periods of high wind speeds and high friction velocities. Another explanation could be a suboptimal delay-time correction because the ECPack software worked with a constant delay between the sonic and the gas analyser. All other software packages applied a cross-correlation analysis for each 30-min interval to determine the delay based on the maximum covariance. The EddySoft results agreed well with TK2, whereas the Alteddy software yielded higher daytime fluxes compared to the reference. Differences in the spectral correction procedure could be a reason for the deviations of Alteddy, ECPack and EdiRE, which occur mostly during daytime under unstable stratification. The absolute correction term for highfrequency losses is largest around solar noon (Mauder and Foken, 2006b). If the Moore correction is applied, the correction depends on wind speed as well as friction velocity. Thus, differences in the implementation of this correction, either in the co-spectral parameterisations or the transfer functions applied, may well explain the findings.

\section{Evaluation of the software packages}

Finally, the overall comparison of the different software packages can be evaluated taking into account the regression analysis presented in Table 3 .

Alteddy: The Alteddy software originating from the ALTERRA institute was able to calculate $\mathrm{CO}_{2}$ fluxes for all four datasets. No systematic deviation from the TK2 could be found for the DE-Wet and G-ATEM datasets, whereas the $\mathrm{CO}_{2}$ fluxes for the DE-Wei and the LIT-A6 site were larger than the TK2 estimates by around $10 \%$. For a few of the $30-$ min intervals of each dataset, Alteddy processing obtained very different flux estimates than the TK2 software and the other software packages. The most likely explanation for that scatter can be ascribed to the data preparation. A different coordinate transformation method or the angle-of-attack calibration are probably the reason.

ECPack: The ECPack software from Wageningen University could only be compared for the LIT-A6 dataset. It systematically underestimated the $\mathrm{CO}_{2}$ flux for the whole range of values compared to the other software packages. These deviations were especially pronounced for larger negative $\mathrm{CO}_{2}$ fluxes during periods of high friction velocity. The reason is possibly a different correction for spectral losses or the assumption of a constant time delay of the gas analyser.

EddySoft: In general, the results of the EddySoft package agreed quite well with those from the TK2, at least for the datasets DE-Wei, DE-Wet and LIT-A6. The set of processing steps of EddySoft was generally similar to those of the TK2 software. Some deviations from TK2 were found for nighttime periods from the G-ATEM dataset, which can probably be attributed to small differences in the spike elimination procedure.

EdiRE: The results of the software EdiRE from the University of Edinburgh show few scatter compared to TK2 software for most datasets. This shows that data preparation and coordinate transformations procedures were similar between both algorithms. A few larger deviations from the TK2 results still occurred for the G-ATEM dataset, especially for nighttime data. They can probably be ascribed to differences in parameter settings of the despiking routine although the same method was applied. During periods of high friction velocities, systematically smaller $\mathrm{CO}_{2}$ fluxes were obtained by EdiRE for the dataset A6 of LITFASS-2003 when compared to the TK2 results. EdiRE calculated slightly larger $\mathrm{CO}_{2}$ flux estimates for the dataset DE-Wet. EdiRE fluxes were $5 \%$ larger for the closed-path system at this site. Differences in the spectral correction can explain this finding. EdiRE uses cospectral models based on Moore (1986) in the corrected form of Moncrieff et al. (1997) for the stable case. These are slightly different from the original cospectral models by Kaimal et al. (1972) and Højstrup (1981), which are used in TK2. Moreover, a transfer function for low-frequency losses due to a finite length of the averaging time and a transfer function for tube attenuation were applied 
in EdiRE as opposed to TK2, which can explain larger $\mathrm{CO}_{2}$ flux estimates than those from TK2 for the DE-Wet dataset.

eth-flux: $\mathrm{CO}_{2}$ fluxes calculated with the eth-flux software and the TK2 agreed quite well for the data from the tall vegetation sites DE-Wei and DE-Wet. These eth-flux estimates were only slightly larger than the ones from TK2, but still statistically significant. The comparison of the low vegetation site G-ATEM showed relatively large scatter, particularly for nighttime data. The use of the 2-D-rotation in combination with block averaging in place of a planar fit transformation is a possible explanation of the observed differences. The eth-flux software did not incorporate a statistical spike elimination routine. Eth-flux and the TK2 software represented two different philosophies on how to perform flux measurements. The developers of the eth-flux software were of the opinion that careful and accurate data acquisition is essential. Therefore, spike removal is only used for instruments such as the one described in Eugster et al. (1997) that are not capable of always delivering correct values or clearly defined missing values. The remaining outliers can then be eliminated during the plausibility check procedure, and if this is done carefully, the remaining potential outliers in any of the time series should have no or very little impact on flux results. Since all data are actually real measurements after all, eth-flux developers are reluctant to eliminate data based on a statistical quality control test. Thereby, they try to avoid the exclusion of important flux contributions. In contrast, the TK2 developers believed that, even if a lot of care is taken on the data acquisition, unrealistic data are unavoidable. They acknowledged that especially the open-path analysers are prone to disturbances in the measuring path, may it be due to snow, rain, dew, fog or insects. Therefore a spike test was applied in TK2, and the number of detected spikes was monitored to be able to investigate a potential error source in the measurement set-up. The eth-flux developers however record all digital data from their IRGAs, which includes invaluable house-keeping variables such as the optical window dirtiness. They consider this is a much better filter for physical plausibility than a purely statistical spike detection routine, which they used 10 years ago as well (see Eugster et al., 1997). Even filtering the data according to the house-keeping variables alone may not account for all effects related to contamination of the windows (Serrano-Ortiz et al., 2008). The However, the CDEF data format does not include this important variable since some research groups do still not record their IRGA data digitally. Thus, for the comparison presented here it was not possible to thoroughly compare which of the approaches at the very end leads to more accurate fluxes. In either case, a fully digital data acquisition (i.e. no conversion of IRGA signals to analog voltage levels which are later converted back for data acquisition via an analog-to-digital converter circuit) that takes benefit of available instrument-specific house-keeping variables will be an essential step forward towards objectively defensible flux computations that depend to a lesser degree on software packages and their implicit assumptions.

TUDD: The TUDD software from the University of Technology Dresden calculated only $\mathrm{CO}_{2}$ fluxes from the DE-Wet site, which was equipped with a closed-path IRGA. Slightly larger fluxes were found compared to TK2 (Fig. 2), indicated by a regression slope of 1.05 . The scatter is relatively small $\left(R^{2}=0.98\right)$. The observed deviations from the TK2 can probably be explained by the use of a 3-D-rotation instead of a planar fit coordinate transformation and differences in the correction for high frequency spectral losses, particularly in the transfer functions applied.

\section{Discussion}

In contrast to internationally accepted and established calibration procedures for instruments measuring mean concentrations or scalar entities, there are no similar procedures available for fluxes. With this lack of an unanimously established absolute standard for flux measurements, it was also not possible to use an independent reference for the flux estimates in this intercomparison study. Although there is no proof that the TK2 results are accurate, the TK2 software was chosen as a reference for this comparison because its single processing steps are well-characterised (Mauder and Foken, 2006a), and it was already tested in another international software comparison (Mauder et al., 2007b). It thus provides the essential linkage between the effort made here and earlier attempts to ascertain a standard flux processing quality in pre-CarboEurope projects. With the exception of some outliers, the results of all software packages agree within a range of $5 \%$ to $10 \%$ on the $30-\mathrm{min}$ time scale. The effect of these differences on daily and annual sums can vary depending if the errors compensate or accumulate for upward and downward fluxes. Over tall vegetation, the TK2 reference was found to be at the low end of the range expressed by the other participating software, whereas over low vegetation some software packages yielded partly lower $\mathrm{CO}_{2}$ fluxes compared to TK2. Since for the two low-vegetation datasets also different sonic types were used than for the tallvegetations sites, an effect of the specific sonic type cannot completely be ruled out. However, it is hard to imagine how a different sonic type could lead to such differences in $\mathrm{CO}_{2}$ fluxes when the computations are based on the same dataset.

As crucial processing steps leading to significant discrepancies in the $\mathrm{CO}_{2}$ flux results were identified:

- Data preparation (spike elimination, delay correction)

- Coordinate rotation (planar fit, 2-D/3-D rotation)

- Application of correction for high frequency spectral losses (Moore approach with different transfer functions, Eugster and Senn correction)

The data preparation is a very important step especially in the case when foreign datasets, where meta-information on 
its theoretical quality is less certain, should be processed. Differences in these procedures before the actual covariance calculation can have a large impact on the resulting $\mathrm{CO}_{2}$ flux estimates. Whilst the plausibility test algorithm can most efficiently and specifically eliminate many known problems of specific instruments and combinations of the software developers' own data acquisition system, it might be preferable to apply an additional more general statistically-based spike detection and elimination procedure for foreign datasets where no a priori information is available on what artefacts in the raw data need to be removed. This is not only important for $\mathrm{CO}_{2}$ and wind data, which are required for the covariance, but also for temperature and humidity data because they are needed for the corrections. Differences also exist in the way implausible data and those detected as spikes are handled. One option is the interpolation of the data gap after despiking, either by repeating the previous non-spike value or by linear interpolation. Another option is to calculate the covariance only with the remaining non-spike values, which has the advantage of not introducing any artificial data but does not allow spectral analysis. At the same time, careful and thorough execution of the measurements regarding the selection of the site, an appropriate choice of instruments, measurement set-up, maintenance and documentation is important to produce high quality data, which require as little as possible automatic filtering and corrections.

All the $\mathrm{CO}_{2}$ flux estimates for this study were calculated on the basis of a 30-min averaging time. One interval had to be chosen to allow an intercomparison between different software packages at all. It was decided to work with 30min flux estimates because this is common practice within CarboEurope-IP. However, there is evidence that a fixed averaging time of 30-min would often lead to a flux bias, usually an underestimation of the total flux during daytime, due to spectral losses in the low-frequency part (Sakai et al., 2001; Finnigan et al., 2003; Foken et al., 2006; Mauder and Foken, 2006b; Mauder et al., 2007a). Moreover, the 5-day datasets might be not sufficiently long to obtain statistically significant regression coefficients. This could be checked using statistical tests. However, this was not part of this software comparison. Still, all software producers started with the same datasets, and they should compute the same fluxes if the underlying assumptions are the same. This study is therefore only a relative intercomparison to identify differences between software without necessarily aiming at estimating the "true flux" for the ecosystems where the datasets were measured.

\section{Recommendations and conclusions}

Based on our experience gained during this software comparison, we recommend that the following unresolved issues should receive specific attention to improve our capability to reproduce defensible eddy covariance fluxes.
From the results of this comparison and the experience of the participating scientists, we conclude that only closedpath IRGAs can provide the highest accuracy of the flux measurements, but also require the largest resources for maintenanceand and usually consume more electrical energy than open-path systems. In contrast, open-path instruments, where more unknown and not easily quantifiable sources of artefacts deteriorate the quality of the flux computation, tend to lead to lower data quality, no matter how high quality the software that processes these data.

Despite the common agreement not to use linear detrending of time series but to use block averaging and planar fit coordinate rotation approach instead we did not yet convincingly solve the issue of highly variable fluxes at certain times where plant physiological knowledge and expertise would suggest much smoother time traces of fluxes. Therefore, further efforts should be made to critically assess how to account for flux components at the low-frequency end of the turbulence spectrum that are partially cut off due to the use of fixed 30-min averaging intervals.

A crucial issue in the data post-processing of eddy fluxes on the basis of a 30-min averaging time is the correction for spectral losses because it can result in systematic biases. An aggravating factor for the comparability of flux estimates is that two conceptually different methods are available to compensate spectral losses (Moore, 1986; Eugster and Senn, 1995), which both have strengths and weaknesses. The inductance values for the Eugster and Senn correction must be adapted to a specific measurement set-up from a spectral analysis. For both the Moore and the Eugster and Senn corrections, the universal applicability of model cospectra and spectra has to be checked. Both corrections assume scalar similarity, which is not always fulfilled and can change for different times of the day (Ruppert et al., 2006b). A different selection of transfer functions can lead to larger differences in flux estimates if the Moore correction is applied. The theoretical misconception of the Moore approach about the simple multiplication of transfer functions, as mentioned by Horst (2000), is another factor that deserves more detailed investigation. A further problem in the case of the Moore (1986) correction is the adaptation of the temperature model spectra for humidity and $\mathrm{CO}_{2}$ because similarity between these scalars.

The overall comparison indicated a good - although not yet perfect - agreement among software packages used in CarboEurope-IP within 5-10\% difference for the 30-min $\mathrm{CO}_{2}$ flux values. In general, results for $\mathrm{CO}_{2}$ fluxes calculated from the same raw data may disagree because of two fundamentally different reasons. Firstly, there are errors in most software that may lead to different results. Ideally, by using and comparing software these errors can be reduced. Secondly, objectives of experiments and people's perception of what problems might have priority are quite varied, people make choices about how the data should be processed, often leading to differences in the results. This second cause of 
errors can hardly be resolved, nor should it, as it allows the critical thinking that is necessary for useful development.

Nevertheless, a common agreement about the processing of eddy covariance fluxes should be aspired within the CarboEurope-IP network, possibly based on the recommendations of Lee et al. (2004). Large consortia such as CarboEurope-IP tend towards more democracy-based than science-based agreements on commonly accepted rules for data processing. This brings with it the conflict that on the one hand all groups should process their data in exactly the same way to minimize systematic differences in flux computations, whereas on the other hand there are significant differences in the needs for forest, grassland, and cropland ecosystems that cannot be easily solved by democratically agreeing on a best practice. Therefore, in the future a more careful division between advancing methodical issues in parallel to monitoring of fluxes in a standardised way should be promoted. Within CarboEurope-IP this is nicely done concerning the open issue about advective influences on net ecosystem exchange (e.g. Aubinet et al., 2003b), but it is easily forgotten that also the standard turbulent flux measurements need a similar critical methodical evaluation and development.

\section{Edited by: T. R. Christensen}

\section{References}

Aubinet, M., Grelle, A., Ibrom, A., Rannik, Ü., Moncrieff, J., Foken, T., Kowalski, A. S., Martin, P. H., Berbigier, P., Bernhofer, C., Clement, R., Elbers, J., Granier, A., Grünwald, T., Morgenstern, K., Pilegaard, K., Rebmann, C., Snijders, W., Valentini, R., and Vesala, T.: Estimates of the annual net carbon and water exchange of forests: The EUROFLUX methodology, Adv. Ecol. Res., 30, 113-175, 2000.

Aubinet, M., Clement, R., Elbers, J. E., Foken, T., Grelle, A., Ibrom, A., Moncrieff, J., Pilegaard, K., Rannik, U., and Rebmann, C.: Methodology for data aquisition, storage and treatment, in: Fluxes of carbon, water and energy of European Forests, 163 ed., edited by: Valentini, R., Ecological Studies, Springer, Berlin, Heidelberg, 9-35, 2003a.

Aubinet, M., Heinesch, B., and Yernaux, M.: Horizontal and vertical $\mathrm{CO}_{2}$ advection in a sloping forest, Bound.-Lay. Meteorol., 108, 397-417, 2003b.

Baldocchi, D., Finnigan, J. J., Wilson, K., Paw U, K. T., and Falge, E.: On measuring ne ecosystem exchange over tall vegetation on complex terrain, Bound.-Lay. Meteorol., 96, 257-291, 2000.

Baldocchi, D., Falge, E., Gu, L. H., Olson, R., Hollinger, D., Running, S., Anthoni, P., Bernhofer, C., Davis, K., Evans, R., Fuentes, J., Goldstein, A., Katul, G., Law, B., Lee, X. H., Malhi, Y., Meyers, T., Munger, W., Oechel, W., U, K. T. P., Pilegaard, K., Schmid, H. P., Valentini, R., Verma, S., Vesala, T., Wilson, K., and Wofsy, S.: FLUXNET: A new tool to study the temporal and spatial variability of ecosystem-scale carbon dioxide, water vapor, and energy flux densities, B. Am. Meteorol. Soc., 82, 2415-2434, 2001.

Beyrich, F. and Mengelkamp, H.-T.: Evaporation over a heterogeneous land surface: EVA_GRIPS and the LITFASS-2003 experi- ment - an overview, Bound.-Lay. Meteorol., 121, 5-32, 2006.

Eugster, W. and Senn, W.: A cospectral correction model for measurements of turbulent $\mathrm{NO}_{2}$ flux, Bound.-Lay. Meteorol., 74, 321-340, 1995.

Eugster, W., McFadden, J. P., and Chapin III, F. S.: A comparative approach to regional variation in surface fluxes using mobile eddy correlation towers, Bound.-Lay. Meteorol., 85, 293-307, 1997.

Falge, E., Baldocchi, D., Olson, R., Anthoni, P., Aubinet, M., Bernhofer, C., Burba, G., Ceulemans, R., Clement, R., Dolman, H., Granier, A., Gross, P., Grunwald, T., Hollinger, D., Jensen, N. O., Katul, G., Keronen, P., Kowalski, A., Lai, C. T., Law, B. E., Meyers, T., Moncrieff, H., Moors, E., Munger, J. W., Pilegaard, K., Rannik, U., Rebmann, C., Suyker, A., Tenhunen, J., Tu, K., Verma, S., Vesala, T., Wilson, K., and Wofsy, S.: Gap filling strategies for defensible annual sums of net ecosystem exchange, Agr. Forest Meteorol., 107, 43-69, 2001.

Finnigan, J. J., Clement, R., Malhi, Y., Leuning, R., and Cleugh, H. A.: A re-evaluation of long-term flux measurement techniques, Part I: Averaging and coordinate rotation, Bound.-Lay. Meteorol., 107, 1-48, 2003.

Foken, T. and Wichura, B.: Tools for quality assessment of surfacebased flux measurements, Agr. Forest Meteorol., 78, 83-105, 1996.

Foken, T., Göckede, M., Mauder, M., Mahrt, L., Amiro, B. D., and Munger, J. W.: Post-field data quality control, in: Handbook of Micrometeorology. A Guide for Surface Flux Measurements, edited by: Lee, X., Massman, W. J., and Law, B. E., Kluwer, Dordrecht, 181-208, 2004.

Foken, T., Wimmer, F., Mauder, M., Thomas, C., and Liebethal, C.: Some aspects of the energy balance closure problem, Atmos. Chem. Phys., 6, 4395-4402, 2006, http://www.atmos-chem-phys.net/6/4395/2006/.

Foken, T.: The energy balance closure problem - an overview, Ecological Applications, accepted, 2008

Gash, J. H. C. and Dolman, A. J.: Sonic anemometer (co)sine response and flux measurement: I. The potential for (co)sine error to affect sonic anemometer-based flux measurements, Agr. Forest Meteorol., 119, 195-207, 2003.

Göckede, M., Rebmann, C., and Foken, T.: A combination of quality assessment tools for eddy covariance measurements with footprint modelling for the characterisation of complex sites, Agr. Forest Meteorol., 127, 175-188, 2004.

Göckede, M., Markkanen, T., Hasager, C. B., and Foken, T.: Update of footprint-based approach for the characterisation of complex measurement sites, Bound.-Lay. Meteorol., 118, 635-655, 2006.

Grelle, A. and Burba, G.: Fine-wire thermometer to correct $\mathrm{CO}_{2}$ fluxes by open-path analyzers for artificial density fluctuations, Agric. For. Meteor., 147, 48-57, 2007.

Højstrup, J.: A simple model for the adjustment of velocity spectra in unstable conditions downstream of an abrupt change in roughness and heat flux, Bound.-Lay. Meteorol., 21, 341-356, 1981.

Højstrup, J.: A statistical data screening procedure, Measuring Science Technology, 4, 153-157, 1993.

Horst, T. W.: On frequency response corrections for eddy covariance flux measurements, Bound.-Lay. Meteorol., 94, 517-520, 2000.

Kaimal, J. C., Wyngaard, J. C., Izumi, Y., and Coté, O. R.: Spectral characteristics of surface layer turbulence, Q. J. Roy. Meteorol. 
Soc., 98, 563-589, 1972.

Kaimal, J. C. and Finnigan, J. J.: Atmospheric Boundary Layer Flows: Their Structure and Measurement, Oxford University Press, New York, NY, 289 pp., 1994.

Kolle, O. and Rebmann, C.: EddySoft - Documentation of a Software Package to Aquire and Process Eddy Covariance Data, Max-Planck-Institut für Biogeochemie, Jena, Technical Report 10, 85 pp., 2007.

Lee, X.: On micrometeorological observations of surface-air exchange over tall vegetation, Agr. Forest Meteorol., 91, 39-49, 1998.

Lee, X., Massman, W., and Law, B. E.: Handbook of Micrometeorology. A Guide for Surface Flux Measurement and Analysis, Kluwer Academic Press, Dordrecht, 250 pp., 2004.

Leuning, R. and King, K. M.: Comparison of eddy-covariance measurements of $\mathrm{CO}_{2}$ fluxes by open-path and closed-path $\mathrm{CO}_{2}$ analysers, Bound.-Lay. Meteorol., 59, 297-311, 1992.

Liu, H., Peters, G., and Foken, T.: New equations for sonic temperature variance and buoyancy heat flux with an omnidirectional sonic anemometer, Bound.-Lay. Meteorol., 100, 459-468, 2001.

Liu, H., Randerson, J. T., Lindfors, J., Massman, W., and Foken, T.: Consequences of incomplete surface energy balance closure for $\mathrm{CO} 2$ fluxes from open-path $\mathrm{CO} 2 / \mathrm{H} 2 \mathrm{O}$ infrared gas analysers, Bound.-Lay. Meteorol., 120, 65-85, 2006.

Mauder, M., Foken, T., Göckede, M., Liebethal, C., Ruppert, J., and Bertolini, T.: Dokumentation des Experiments LITFASS2003, 19.05.2003 bis 20.06.2003, Dokumentation des Experimentes GRASATEM-2003, 14.05.2003 bis 01.06.2003, Universität Bayreuth, Abt. Mikrometeorologie, Print, ISSN 1614-8916, Arbeitsergebnisse 23, 47 pp., 2003.

Mauder, M. and Foken, T.: Documentation and instruction manual of the eddy covariance software package TK2, Universität Bayreuth, Abt. Mikrometeorologie, Print, ISSN 1614-8916, Arbeitsergebnisse, 26, 44 pp., 2004.

Mauder, M. and Foken, T.: Impact of post-field data processing on $\mathrm{CO}_{2}$-flux estimates from eddy covariance measurements, 40th CMOS Congress, Toronto, Canada, abstract online and on CD, 2006a.

Mauder, M. and Foken, T.: Impact of post-field data processing on eddy covariance flux estimates and energy balance closure, Meteor. Z., 15, 597-609, 2006b.

Mauder, M., Liebethal, C., Göckede, M., Leps, J.-P., Beyrich, F., and Foken, T.: Processing and quality control of flux data during LITFASS-2003, Bound.-Lay. Meteorol., 121, 67-88, 2006.

Mauder, M., Desjardins, R. L., and MacPherson, J. I.: Scale analysis of airborne flux measurements over heterogeneous terrain in a boreal ecosystem, J. Geophys. Res., 112, D13112, doi:13110.11029/12006JD008133, 2007a.

Mauder, M., Oncley, S. P., Vogt, R., Weidinger, T., Ribeiro, L., Bernhofer, C., Foken, T., Kohsiek, W., de Bruin, H. A. R., and Liu, H.: The Energy Balance Experiment EBEX-2000. Part II: Intercomparison of eddy-covariance sensors and post-field data processing methods, Bound.-Lay. Meteorol., 123, 29-54, $2007 \mathrm{~b}$.

Moncrieff, J. B., Massheder, J. M., DeBruin, H., Elbers, J., Friborg, T., Heusinkveld, B., Kabat, P., Scott, S., Søgaard, H., and Verhoef, A.: A system to measure surface fluxes of momentum, sensible heat, water vapor and carbon dioxide, J. Hydrol., 188-189, 589-611, 1997.

Moore, C. J.: Frequency response corrections for eddy correlation systems, Bound.-Lay. Meteorol., 37, 17-35, 1986.

Oncley, S. P., Foken, T., Vogt, R., Kohsiek, W., de Bruin, H., Bernhofer, C., Christen, A., Grantz, D., Lehner, E., Liebethal, C., Liu, H., Mauder, M., Pitacco, A., Ribeiro, L., and Weidinger, T.: The Energy Balance Experiment EBEX-2000. Part I: Overview and energy balance, Bound.-Lay. Meteorol., 123, 1-28, 2007.

Pearson Jr., R. J., Oncley, S. P., and Delany, A. C.: A scalar similarity study based on surface layer ozone measurements over cotton during the California Ozone Deposition Experiment, J. Geophys. Res., 103, 18 919-18 926, 1998.

Ruppert, J., Mauder, M., Thomas, C., and Lüers, J.: Innovative gapfilling strategy for annual sums of $\mathrm{CO}_{2}$ net ecosystem exchange, Agr. Forest Meteorol., 138, 5-18, 2006a.

Ruppert, J., Thomas, C., and Foken, T.: Scalar similarity for relaxed eddy accumulation methods, Bound.-Lay. Meteorol., 120, 3963, 2006b.

Sakai, R. K., Fitzjarrald, D. R., and Moore, K. E.: Importance of low-frequency contributions to eddy fluxes observed over rough surfaces, J. Appl. Meteor., 40, 2178-2192, 2001.

Schotanus, P., Nieuwstadt, F. T. M., and DeBruin, H. A. R.: Temperature measurement with a sonic anemometer and its application to heat and moisture fluctuations, Bound.-Lay. Meteorol., 26, 81-93, 1983.

Serrano-Ortiz, P., Kowalski, A. S., Domingo, F., Ruiz, B., and Adalos-Arboledas, L.: Consequences of uncertainties in $\mathrm{CO}_{2}$ density for estimating net ecosystem $\mathrm{CO} 2$ exchange by openpath eddy covariance, Bound.-Lay. Meteorol., 126, 209-218, 2008.

Staebler, R. M. and Fitzjarrald, D. R.: Observing subcanopy $\mathrm{CO}_{2}$ advection, Ag. Forest Meteorol., 122, 139-156, 2004.

Tanner, B. D., Swiatek, E., and Greene, J. P.: Density fluctuations and use of the krypton hygrometer in surface flux measurements, in: Management of irrigation and drainage systems: integrated perspectives, edited by: Allen, R. G., American Society of Civil Engineers, New York, NY, 945-952, 1993.

van der Molen, M. K., Gash, J. H. C., and Elbers, J. A.: Sonic anemometer (co)sine response and flux measurement: II. The effect of introducing an angle of attack dependent calibration, Agr. Forest Meteorol., 122, 95-109, 2004.

van Dijk, A., Kohsiek, W., and DeBruin, H. A. R.: Oxygen sensitivity of krypton and Lyman-alpha hygrometers, J. Atmos. Oceanic Technol., 20, 143-151, 2003.

van Dijk, A., Kohsiek, W., and de Bruin, H. A. R.: The principles of surface flux physics: theory, practice and description of the ECPACK librarypp., 2004.

Vickers, D. and Mahrt, L.: Quality control and flux sampling problems for tower and aircraft data, J. Atmos. Oceanic Technol., 14, 512-526, 1997.

Webb, E. K., Pearman, G. I., and Leuning, R.: Correction of the flux measurements for density effects due to heat and water vapour transfer, Q. J. Roy. Meteorol. Soc., 106, 85-100, 1980.

Wilczak, J. M., Oncley, S. P., and Stage, S. A.: Sonic anemometer tilt correction algorithms, Bound.-Lay. Meteorol., 99, 127-150, 2001.

Wilson, K., Goldstein, A., Falge, E., Aubinet, M., Baldocchi, D., Berbigier, P., Bernhofer, C., Ceulemans, R., Dolman, H., and Field, C.: Energy balance closure at FLUXNET sites, Agr. Forest Meteorol., 113, 223-243, 2002. 